\title{
EFFECTS OF DISPERSION AND SUPPORT ON ADSORPTION, CATALYTIC AND ELECTRONIC PROPERTIES OF COBALT/ALUMINA CO HYDROGENATION CATALYSTS
}

Final Progress Report

For the period

August 1, 1987 to July 31,1990

\section{by}

Calvin H. Bartholomew

BYU Catalysis Laboratory

Department of Chemical Engineering

Brigham Young University

Provo, Utah 84602

September 29, 1990

prepared for

U.S. Department of Energy

Office of Basic Energy Sciences

Division of Chemical Sciences

Attention: Dr. William S. Millman

Processes and Techniques Branch

DOE Grant No. DE-FG02-87ER13763

NOTICE

This report was prepared as an account of work sponsored by the Unilad States Government. Neither the United States nor the Department of Energy, nor any of their employees, nor any of their contractors, subcontractors, or their employees, makes any warranty, express or implied, or assumes any legal liability or responsibility for the accuracy, completeness, or usefulness of any information, apparatus, product or process disclosed or represents that its use would not infringe privately-owned rights. 


\begin{abstract}
An investigation of the effects of surface structure, dispersion, and support on the adsorption, catalytic, and electronic properties of cobalt/alumina is described, the objectives of which were to determine (1) the effects of surface structure and metal dispersion on the adsorption and catalytic properties of cobalt and (2) the effects of direct electronic interactions between metal clusters and support, on the adsorption, catalytic and electronic properties of cobalt supported on alumina. Effects of surface structure and dispersion on the adsorption, activity/selectivity, and electronic properties of $\mathrm{Co} / \mathrm{W}$ single crystal surfaces and aluminasupported cobalt were investigated in a surface science investigation, lab reactor studies, TPD/TPSR studies, and a Moessbauer spectroscopy study.

The structure, stability, surface electronic properties, and chemisorptive properties of vapor-deposited cobalt overlayers $(0-4 \mathrm{ML})$ on $W(110)$ and $W(100)$ were studied by Auger electron spectroscopy, low energy electron diffraction, work function changes, and temperature programmed desorption (TPD) of cobalt, hydrogen, and carbon monoxide. The CO chemisorptive properties of the two cobalt overlayers are quite different, $\mathrm{CO}$ adsorption being dissociative on the $W(100)$ surface and nondissociative on the $W(110)$ surface; comparison of the results with those for $\mathrm{Ni} / \mathrm{W}(100)$ indicate that $\mathrm{CO} / \mathrm{W}(100)$ dissociates $\mathrm{CO}$ as a result of electronic interaction with the tungsten substrate.

Activities and selectivities of cobalt/alumina catalysts for $\mathrm{CO}$ hydrogenation prepared by decomposition of $\mathrm{CO}_{4}(\mathrm{CO})_{12}$ were determined as functions of metal loading, dispersion, and extent of reduction. Steady-state activity was found to be independent of cobalt metal dispersion over the range of $6-37 \%$ ( 0 to $100 \%$ if $\mathrm{Co}$ and $\mathrm{Co} / \mathrm{W}$ surfaces were included) but increases with increasing extent of reduction. TPD/TPSR studies of supported cobalt catalysts prepared by conventional impregnation and by carbonyl-derived catalysts indicate that $1 \%$ Co catalysts have little or no activity for $\mathrm{CO}$ hydrogenation and do not dissociate $\mathrm{CO}$; the observed decreasing activity with decreasing metal loading may be due in part to decoration by the support. Moessbauer spectroscopy data obtained for $0.5-2 \% \mathrm{Fe}^{57}$ /alumina catalysts provide evidence of a superparamagnetic metallic phase, the electronic properties of which are apparently different than bulk iron, possibly due to direct interaction with the support.
\end{abstract}

\title{
DISCLAIMER
}

This report was prepared as an account of work sponsored by an agency of the United States Governmerrt. Neither the United States Government nor any agency thereof, nor any of their employees, makes any warranty, express or implied, or assumes any legal liability or responsibility for the accuracy, completeness, or usefulness of any information, apparatus, product, or process disclosed, or represents that its use would not infringe privately owned rights. Reference herein to any specific commercial product, process, or service by trade name, trademark, manufacturer, or otherwise does not necessarily constitute or imply its endorsement, recommendation, or favoring by the United States Government or any agency thereof. The views and opinions of authors expressed herein do not necessarily state or reflect those of the United States Government or any agency thereof. 


\section{INTRODUCTION}

Cobalt, iron and nickel catalysts find wide application in the fuels and chemical industries, particularly in hydrogenation and hydrotreating reactions. Most commercial catalysts containing these metals consist of a metal, metal oxide, or metal sulfide phase dispersed throughout a high surface area ceramic carrier or "support." The purpose of the support is basically twofold: (i) to facilitate the preparation of a well-dispersed, high surface area catalytic phase and (ii) to stabilize the active phase against loss of surface area. "The effects of surface structure, dispersion and support on activity and selectivity of the active catalytic phase were assumed until recent times to be of secoridary importance. However, evidence published mostly in the past decade provides evidence that surface structure/ dispersion [1-4] and metal-support interactions [5-8] can dramatically influence the adsorption and activity/selectivity properties of thee metals in a number of reactions. While it is desirable to study separately the effects of surface structure, dispersion and metal-support interactions, it is experimentally difficult to achieve since these effects are often interrelated. During the past ten years, the BYU Catalysis Laboratory has been involved in an investigation of the effects of surface structure, dispersion, and support on the adsorption, catalytic, and electronic properties of cobalt. A new phase of this work which emphasizes the effects of dispersion and support on the adsorption, catalytic and electronic properties of cobalt supported on alumina funded by the present grant was initiated August 1,1987 . The results of this investigation conducted over these past 3 years are summarized in this brief report.

\section{RESEARCH SCOPE AND OBJECTIVES}

An investigation of the effects of surface structure, dispersion, and support on the adsorption, catalytic, and electronic properties of cobalt/alumina was conducted, the objectives of which were to: (1) determine the effects of surface structure and metal dispersion on the adsorption and catalytic properties of cobalt and (2) determine the effects of direct electronic interactions between metal clusters and support, on the adsorption, catalytic and electronic properties of cobalt supported on alumina.

To accomplish the above-listed objectives the proposed work was divided into three areas of investigation: (1) study of the effects of surface structure on the adsorption and catalytic properties of cobalt monolayers deposited on $W(100)$ and $W(110)$ using TPD, LEED and AES spectroscopies, and in situ CO hydrogenation reaction measurements, (2) study of the effects of dispersion and metal loading on the $\mathrm{CO}$ adsorption/desorption and catalytic properties of well-dispersed Colalumina and Co-W/alumina using TPD and IR spectroscopies and lab reactor measurements, and (3) Moessbauer study of the effects of metal-support interactions on the electronic properties of well-dispersed cobalt/alumina and iron/alumina. 


\section{SUMMARY OF ACCOMPLISHMENTS}

During the tenure of the present three year grant, the effects of surface structure and dispersion on the adsorption, activity/selectivity and electronic properties of Co/W single crystal surfaces and alumina-supported cobalt were investigated in a surface science investigation, lab reactor studies, TPD/TPSR studies, and a Moessbauer spectroscopy study. The results have been reported in presentations at national meetings [9-12], dissertations/theses [13-16], and journal publications [17-21]. Accomplishments during this period are summarized below.

\section{A. Task 1: Surface Science Investigation of the Adsorption and Catalytic Properties of Cobalt Overlayers on $W(100)$ and $W(110)$ Surfaces.}

The structure, stability, surface electronic properties, and chemisorptive properties of vapor-deposited cobalt overlayers $(0-4 \mathrm{ML})$ on $W(110)$ and $W(100)$ were studied by Auger electron spectroscopy (AES), low energy electron diffraction (LEED), work function changes, and temperature programmed desorption (TPD) of cobalt, hydrogen, and carbon monoxide. The results indicate that the first layer of cobalt grows pseudomorphically with respect to the tungsten substrate, and is thermally stable to $1300 \mathrm{~K}$. Second and subsequent layers grow layer-by-layer at $100 \mathrm{~K}$, but form three-dimensional clusters above 400-500 $\mathrm{K}$. The relative work functions of these surfaces are strongly dependent on temperature, coverage, and substrate geometry. The annealed pseudomorphic monolayer of $\mathrm{Co} / \mathrm{W}(100)$ has a positive work function change $(+155 \mathrm{mV})$, indicating a net electronic charge transfer from the tungsten to the cobalt. The chemisorptive properties of the cobalt overlayers are quite different from those of planar cobalt surfaces, the former having two new binding states for hydrogen chemisorption and two sites for carbon monoxide dissociation. $\mathrm{CO}$ dissociates on cobalt-tungsten interfacial sites and on the pseudomorphic monolayer of $\mathrm{Co} / \mathrm{W}(100)$ as it does on stepped single crystals of cobalt. By comparison of the work function behavior or Ni/W(100) having essentially the same geometry as its cobalt counterpart it can be inferred that the pseudomorphic monolayer of $\mathrm{CO} / \mathrm{W}(100)$ dissociates $\mathrm{CO}$ as a result of electronic interaction with the tungsten substrate, not because of geometric strain. Further details of the characterization of the Co/W surfaces are described in a Ph. D. dissertation by B. G. Johnson [14] and in a paper published in Surface Science [17]

The CO hydrogenation activity of the Co/W(100) surface was measured in the range of 100-500 Torr total pressure and $453-523 \mathrm{~K}$ at a $\mathrm{H}_{2} / \mathrm{CO}$ ratio of $2 / 1$. The specific activity per site was found to be about the same as that for polycrystalline cobalt [9] and independent of initial surface structure for the $\mathrm{CO} / \mathrm{W}(100)$ and $\mathrm{Co} / \mathrm{W}(110)$ surfaces (see Fig. 1). AES spectra show the after-reaction Co/W surfaces to have high coverages of both carbon and 
oxygen, with carbon lineshapes characteristic of carbidic carbon. CO hydrogenation activity of both Co/W surfaces is apparently not correlated with surface carbon level. Thus, CO hydrogenation on cobalt appears to be neither primary nor secondary structure sensitive. Further details of the study of $\mathrm{CO}$ hydrogenation on Co/W surfaces are described in the Johnson dissertation [14] and a submitted paper [18].

\section{B. Task 2: Study of Effects of Dispersion on the CO Adsorption/Desorption and Catalytic Properties of Cobalt/alumina and CoW/alumina.}

1. Lab Reactor Study of the Effects of Dispersion and Extent of Reduction on CO Hydrogenation Activity/Selectivity of Co/alumina and CoW/alumina. Activities and selectivities of cobalt/alumina catalysts for $\mathrm{CO}$ hydrogenation prepared by decomposition of $\mathrm{Co}_{4}(\mathrm{CO})_{12}$ on dehyroxylated gamma alumina were determined as functions of metal loading (1-5\%), dispersion (5-20\%), and extent of reduction (38-95\%). Carbonylderived $\mathrm{Co} /$ dehydroxylated-alumina catalysts have high extents of reduction, high dispersions, and good activity stability. Increasing the dehydroxylation temperature of the alumina support increases the dispersion and extent of reduction. Specific $\mathrm{CO}$ hydrogenation activity is constant over the range of dispersion of $5-37 \%$ for highly reduced 3 and $5 \%$ Co/alumina catalysts and over the entire range of dispersion (0-100\%) if polycrystalline Co and Co/W surfaces are included (see Fig. 2). On the other hand, the activity of poorly reduced 1 and $3 \%$ Co/alumina decreases with increasing dispersion (Fig. 2). The specific activity of carbonyl-derived catalysts increases with the extent of reduction and the support dehydroxylation temperature. Thus, activity is apparently not influenced by dispersion or surface structure by rather by support and/or promoter effects. Further details of the preparation, characterization and reaction study of Co/alumina catalysts are described in the Johnson dissertation [14], a paper published in Catalysis Today [19] and a submitted paper [18].

2. TPD/TPSR/IR Study of the Effects of Support, Metal Loading, and Extent of Reduction on CO Adsorption Kinetics and Energetics of Cobalt. Temperatureprogrammed desorption/ternperature-programmed surface reaction (TPD/TPSR) studies of CO and $\mathrm{CO}$ hydrogenation on cobalt catalysts supported on alumina, silica, titania, and magnesia prepared by conventional means have been written up in a Ph.D. dissertation by Dr. Won Ho Lee [13], a paper published in the Journal of Catalysis [20] and 4-5 associated publications still in preparation. Further TPD/TPSR studies of Co/alumina catalysts prepared from $\mathrm{Co}_{4}(\mathrm{CO})_{12}$ are described in an M.S. Thesis presently still in preparation [16].

TPD study of CO desorption from Co/alumina catalysts [13] indicates that $\mathrm{CO}$ is more strongly adsorbed and dissociates more readily (forming $\mathrm{CO}_{2}$ ) on catalysts of higher loading and of higher reduction temperature. For example, the $\mathrm{CO}$ desorption spectrum for $1 \% \mathrm{Co} /$ alumina consists of one $\mathrm{CO}$ peak at $85^{\circ} \mathrm{C}$ with a heat of adsorption of only $11 \mathrm{kcal} / \mathrm{mol}$ (compared to 14 
$\mathrm{kcal} /$ mole for unsupported $\mathrm{Co}$ ) consistent with weakened desorption of molecular $\mathrm{CO}$; no $\mathrm{CO}_{2}$ desorption is observed suggestirig that $\mathrm{CO}$ does not dissociate on the $1 \%$ catalyst. The CO TPD spectrum for $3 \%$ Co/alumina is similar with a large peak for molecular desorption at $95^{\circ} \mathrm{C}$ and small peaks at 250 and $350^{\circ} \mathrm{C}$ assignable to strongly held molecular and recombinative CO; there is a small $\mathrm{CO}_{2}$ peak at about $350^{\circ} \mathrm{C}$ indicating a small amount of $\mathrm{CO}$ dissociation on this sample. Larger fractions of $\mathrm{CO}$ are desorbed as recombinative $\mathrm{CO}$ and as $\mathrm{CO}_{2}$ on $10 \%$ and $15 \%$ $\mathrm{Co} / a$ lumina catalysts, indicating that $\mathrm{CO}$ is more strongly adsorbed and dissociates more readily on cobalt catalysts of higher loading.

$\mathrm{CO}$ hydrogenation was studied on the same four $(1,3,10$ and $15 \mathrm{wt} . \%) \mathrm{Co} / \mathrm{Al}_{2} \mathrm{O}_{3}$ catalysts using TPSR of adsorbed $\mathrm{CO}$ with $\mathrm{H}_{2}[13,20]$. Two distinct methane peaks (Peaks $\mathrm{A}$ and B) are observed for 3,10 and $15 \% \mathrm{Co}_{\mathrm{Al}} \mathrm{O}_{3}$ during TPSR of chemisorbed $\mathrm{CO}$ at room temperature, indicating the presence of two different reaction states or mechanisms for $\mathrm{CO}$ hydrogenation ( $A$ and $B$ ) (see Fig. 2). No methane peak is observed for $1 \% \mathrm{Co} / \mathrm{Al}_{2} \mathrm{O}_{3}$ unless it is reduced at $1023 \mathrm{~K}$. The more active $A$ state, the relative population of which increases with increasing metal loading and increasing extent of reduction, probably corresponds to hydrogenation of atomic carbon on 3D cobalt crystallites while the less active $B$ state is assigned to decomposition on metal crystallites of a methoxy or formate species originally formed on the support from spilled-over hydrogen and carbon monoxide. TPSR spectra of hydrogen with carbon deposited by $C O$ dissociation at $523 \mathrm{~K}$ show that the quantity of active $\alpha$-carbon increases with increasing metal loading and correlates with the relative population of $A$ sites. $A$ linear correlation beiween logarithm of the steady-state methane turnover frequency and the relative population of $A$ sites suggests that large variations in the steady-state $C O$ hydrogenation with dispersion and metal loading observed for these catalysts may be explained at least in part in terms of variations in the distribution of reaction states for CO hydrogenation, i.e., a larger fraction of Reaction $A$ at higher metal loadings and higher extents of reduction. These TPSR data also show a trend of increasing activity with increasing metal loading (and decreasing dispersion). When compared in light of the TPD results there is a correlation of higher activity for the catalysts which bind $\mathrm{CO}$ more strongly and on which $\mathrm{CO}$ dissociates more readily.

The adsorption/desorption kinetics and energetics of carbon monoxide on carbonyl-derived cobalt catalysts supported on alumina were also studied by TPD, while CO hydrogenation on these same catalysts were studied by TPSR as functions of dispersion and extent of reduction as a continuation of our previous study [16]. In many ways the results obtained were similar to those obtained in the previous study of conventional catalysts. However, there are some important differences including higher activity for low loading catalysts prepared from the carbonyl which suggest that the lower activity of the conventional catalyst may be attributed to decoration by the support. 


\section{Task 3: Study of the Effects of Metal-Support Interactions on the Electronic}

Properties of Well-Dispersed Iron/Alumina. A Moessbauer spectroscopy study of metal-support interactions in alumina-supported iron catalysts (0.5-2 wt.\%) prepared by nonaqueous deposition of isotopic $\mathrm{Fe}^{57}$ chloride on partially dehydroxylated alumina and reduced at high temperatures to obtain well-reduced, highly dispersed metals was carried out. The chemistry and dispersion of the small iron crystallites thus deposited were studied by in situ Mössbauer spectroscopy, $\mathrm{H}_{2}$ chemisorption and $\mathrm{O}_{2}$ titration [15,21]. After exposure to $\mathrm{H}_{2}$ at high temperatures (>673 K) these dilute Fe/alumina catalysts are relatively highly reduced and highly dispersed. Mössbauer spectra reveal that the main iron phases found on the support after reduction at less than $773 \mathrm{~K}$ are superparamagnetic metallic $\mathrm{Fe}^{0}$ (IS $=-0.08 \mathrm{~mm} / \mathrm{s}$ ) and $\mathrm{Fe}^{2+}(\mathrm{IS}=1.08 \mathrm{~mm} / \mathrm{s}, \mathrm{QS}=1.65 \mathrm{~mm} / \mathrm{s})$. Ferromagnetic iron is observed in $2 \%$ Fe/alumina reduced at $873 \mathrm{~K}$ and higher. Small superparamagnetic particles (dia $<6 \mathrm{~nm}$ ) are not easily detected by zero-magnetic field Mössbauer experiments with the exception of a $2 \%$ Fe/aiumina sample reduced at $873 \mathrm{~K}$; in this latter case the presence of a singlet for superparamagnetic metallic iron is highly evident [Fig. 3]. These results combined with chemisorption and $\mathrm{O}_{2}$ titration data suggest a reduction sequence as follows $\mathrm{Fe}^{3+} \rightarrow \mathrm{Fe}^{2+}$ (octahedral coordination) $\rightarrow$

$\mathrm{Fe}^{0}$ (superparamagnetic) $\rightarrow \mathrm{Fe}^{0}$ (ferromagnetic). Some of the $\mathrm{Fe}^{2+}$ (probably in tetrahedral coordination sites) is irreducible.

\section{REFERENCES}

1. Boudart, M. and Djega-Mariadassou, G., Kinetics of Heterogeneous Catalytic Reactions, p. 207, Princeton University Press, Princeton, 1984.

2. Boudart, M., and MCDonald, M. A., "Structure Sensitivity of Hydrocarbon Synthesis from CO and H2," J. Phys. Chern. 88, 2185 (1984).

3. Goodman, D. W., "Model Catalytic Studies over Metal Single Crystals," Acc. Chem. Res. 17, 194 (1984).

4. Somorjai, G. A. and Carrazza, J., Structure Sensitivity of Catalytic Reactions," Ind. Eng. Chem. Fund. 25, 63 (1986).

5. Metal-support and Metal-additive Effects in Catalysis, Imelik et al. Editors, Elsevier Scientific Publishing Co., Amsterdam, 1982.

6. Catalytica Associates, Inc., New Catalytic Materials: Volume X. Metal Support Interactions: Implications for New Catalyst Technologies, Multiclient Study, 4184 MS, 1984 .

7. "Symposium on Strong Metal-Support Interactions," American Chemical Society, Div. Petr. Chem. Preprints 30(1), 1985. 
8. Oukaci, R., Blackmond, D. G., Sayari, A., and Goodwin, J. G., Jr., "The Implications of Metal-Support Interactions on Chemisorption Characterization of Supported Metal Catalysts," in Metal-Support Interactions, ed. by B. Davis, Van Nostrand Reinhold Co., Inc., New York, 1987.

9. Bartholomew, C. H. , Greenlief, C. M., Berlowitz, P. J., Johnson, B. G., and Goodman, D. W., "CO Hydrogenation on Clean Cobalt," presented at the 10th North American Catalysis Society Meeting, San Diego, May 17, 1987.

10. Johnson, B. G., Berlowitz, P. J., Goodman, D. W., and Bartholomew, C. H., "The Structural and Chemisorptive Properties of Ultrathin Cobalt Overlayers on $W(110)$ and $W(100), "$ presented at the 11th North American Catalysis Society Meeting, Dearborn, MI, May 7-11, 1989.

11. Bartholomew, C. H., Neubauer, L. R., and Lee, W. H., "Adsorption, Catalytic and Electronic Properties of Dilute Cobalt/Alumina Catalysts," presented at the 11th North American Catalysis Society Meeting, Dearborn, MI, May 7-11, 1989.

12. Bartholomew, C. H., "The Role of Surface Structure and Dispersion in CO Hydrogenation on Alumina-Supported Cobalt and Iron," Advanced In Catalytic Chemistry IV, Snowbird, Utah, October 1-6, 1989.

13. Lee, W. H., "Temperature-Programmed Desorption and Surface Reaction Studies of Carbon Monoxide on Unsupported and Supported Cobalt Catalysts," Ph. D. Dissertation, Brigham Young University, June 1988.

14. Johnson, B. G., "The Role of Surface Structure in Carbon Monoxide Hydrogenation on Cobalt Catalysts," Ph.D Dissertation, Brigham Young University, July 1989.

15. Smith, P. A., "Reduction and Oxidation Behavior of Iron on Alumina Catalysts of Low Loading," M. S. Thesis, Brigham Young University, August, '1990.

16. Helvy, R, "Temperature Programmed Desorption and Reaction Studies of Cobalt/Alumina Catalysts P:epared from Carbonyls," M. S. Thesis, Brigham Young University, est. Jan., 1991.

17. Johnson, B. G., Berlowitz, P. J., Goodman, D. W., and Bartholomew, C. H., "The Structural and Chemisorptive Properties oi Ultrathin Cobalt Overlayers on $W(110)$ and $W(100)$," Surf. Sci. 217, 13 (1989).

18. Johnson, B. G., Bartholomew, C. H., and Guodman, D. W., "The Role of Surface Structure in CO Hydrogenation on Cobalt," submitted, 1989.

19. Johnson, B. G., Rameswaren, Patil, M. D., Muralidhar, G, and Bartholomew, C. H., "Physical Properties and Fischer-Tropsch Activities of $\mathrm{Co} / \mathrm{Al}_{2} \mathrm{O}_{3}$ Catalysts Prepared from the Decomposition of $\mathrm{CO}_{4}(\mathrm{CO})_{12}$," Catalysis Today 6,81 (1989).

20. Lee, W. H. and Bartholomew, C. H., "Multiple Reaction States in CO Hydrogenation on Alumina-Supported Cobalt Catalysts," J. Catal. 120, 256 (1989).

21. Smith, P. A. and Bartholomew, C. H., "Reduction/Oxidation Behavior of Iron/Alumina Catalysts of Low Loading," submitted, 1990. 


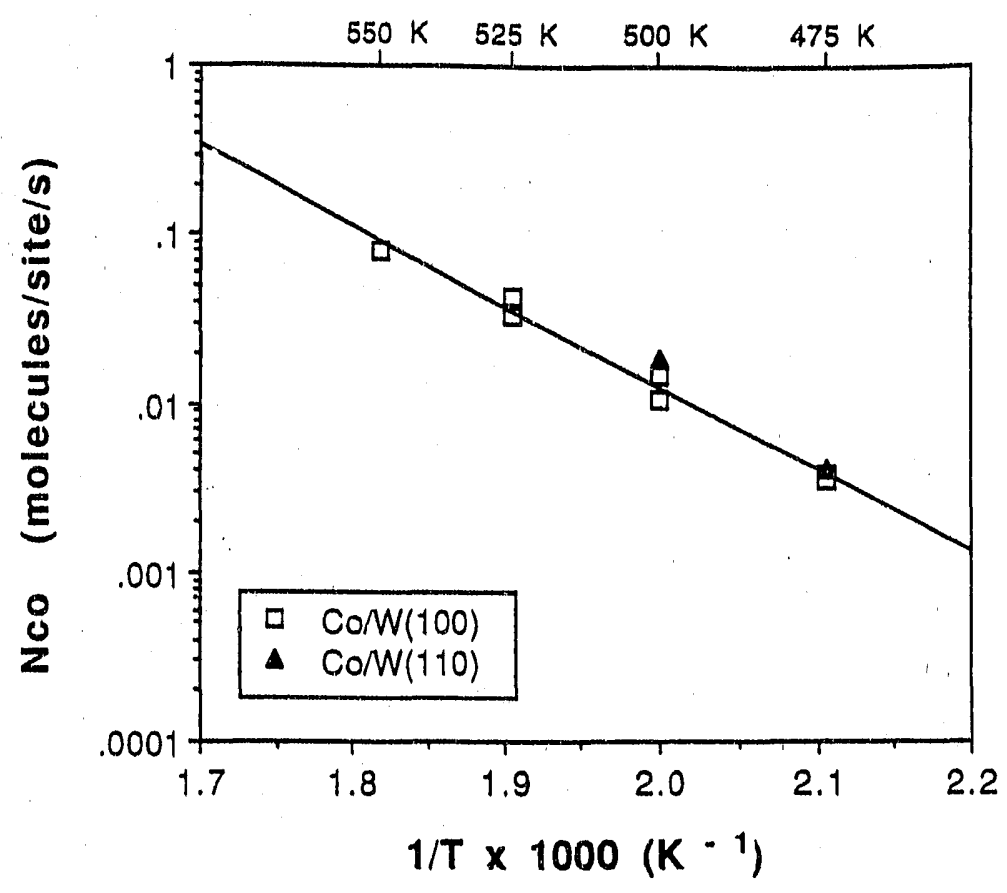

Figure 1. Arrhenius plot for the steady-state CO turnover frequencies of $0.75 \mathrm{ML} \mathrm{Co} / \mathrm{W}(100)$ and $\mathrm{Co} / \mathrm{W}(110)$ at 750 Torr and $\mathrm{H}_{2} / \mathrm{CO}=2$.

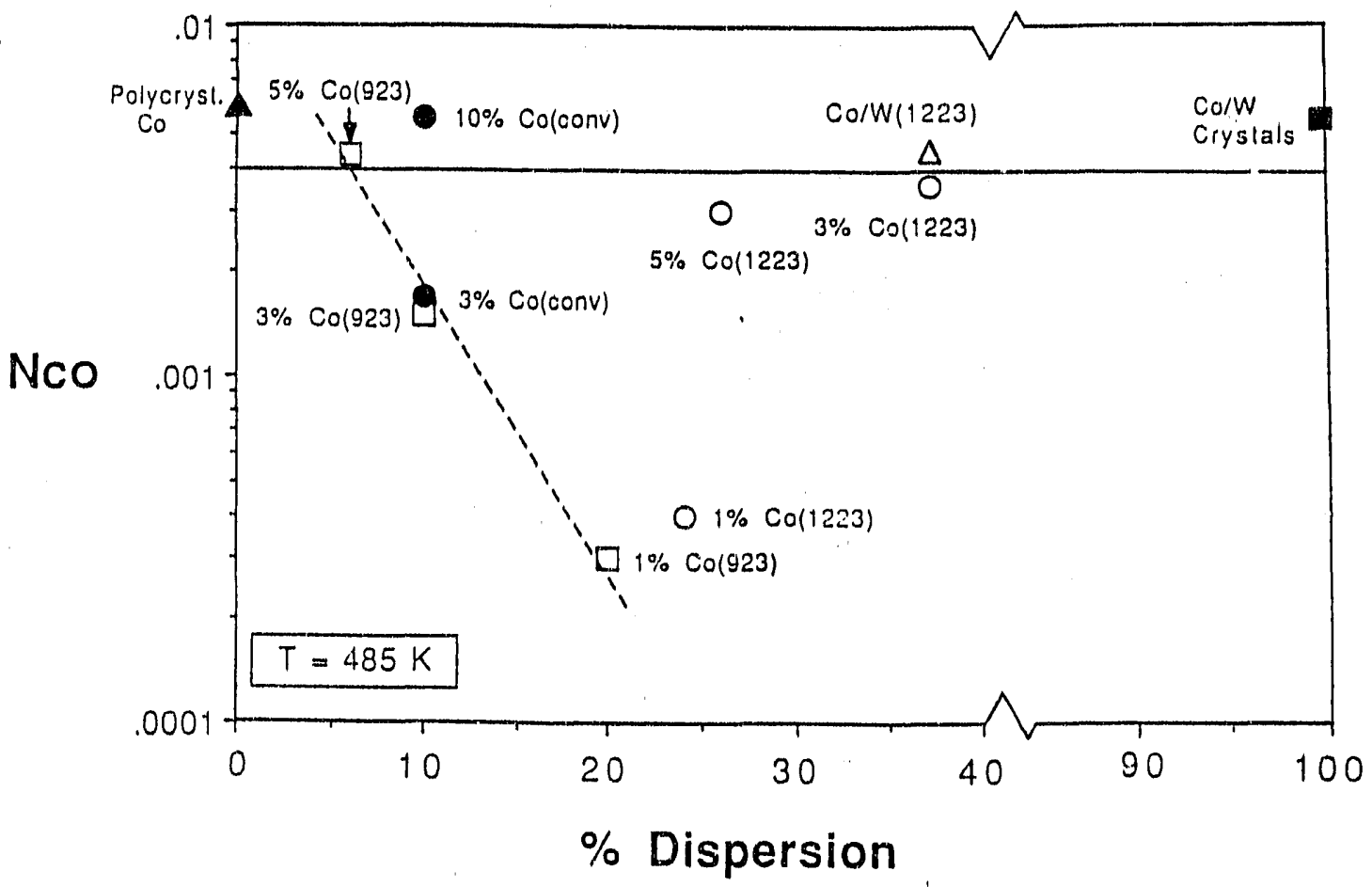

Figure 2. Carbon monoxide turnover frequency (485 $\mathrm{K}, 1 \mathrm{~atm}, \mathrm{H}_{2} / \mathrm{CO}=2$ ) versus \% dispersion of cobalt catalysts (923 or 1223 refers to the temperature of dehydroxylation of support in K). 


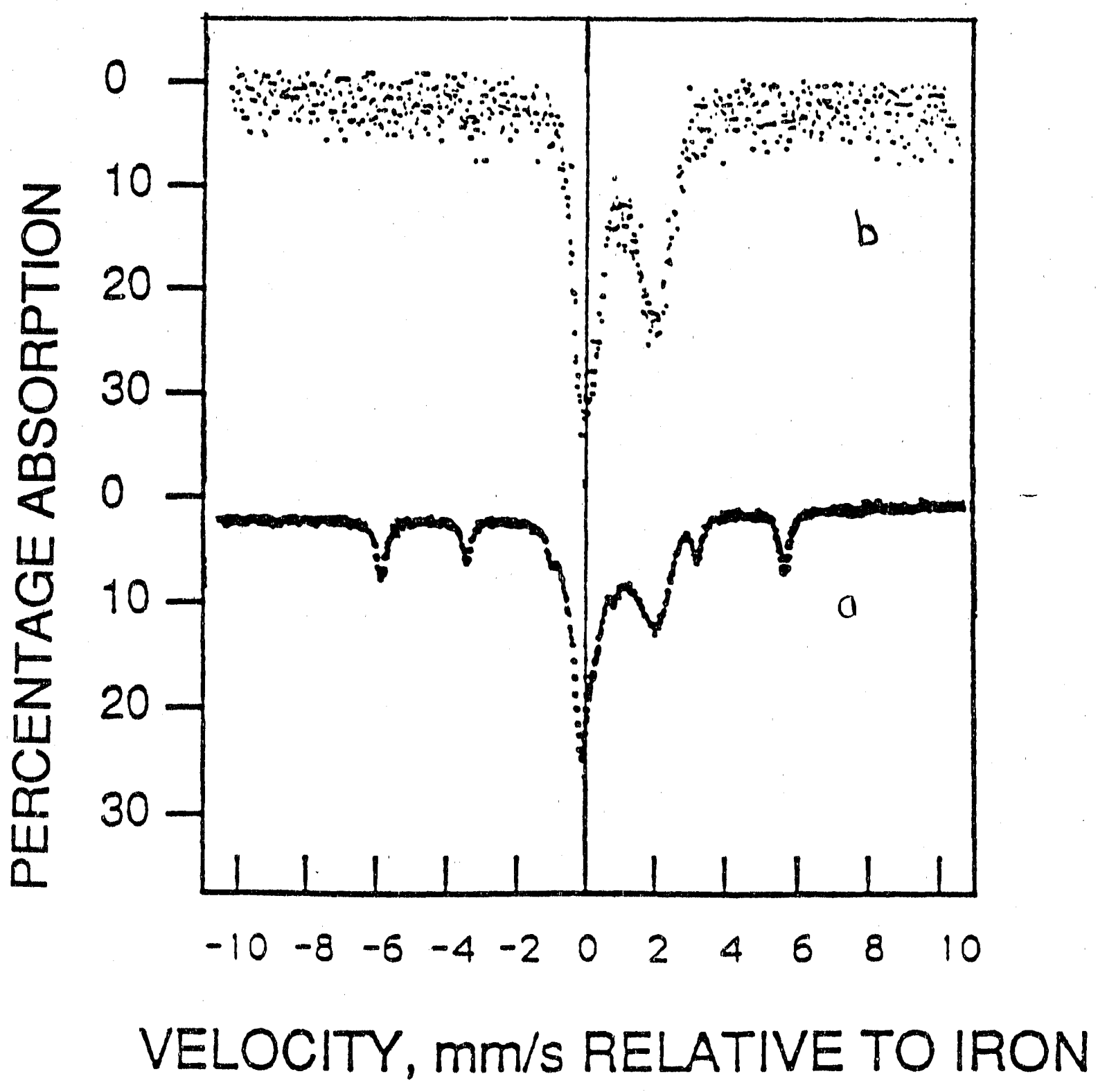

Fig. 3. Moessbauer spectra of $2 \%$ Fe/alumina

(a) reduced at $773 \mathrm{~K}$, (b) reduced at $873 \mathrm{~K}$. 

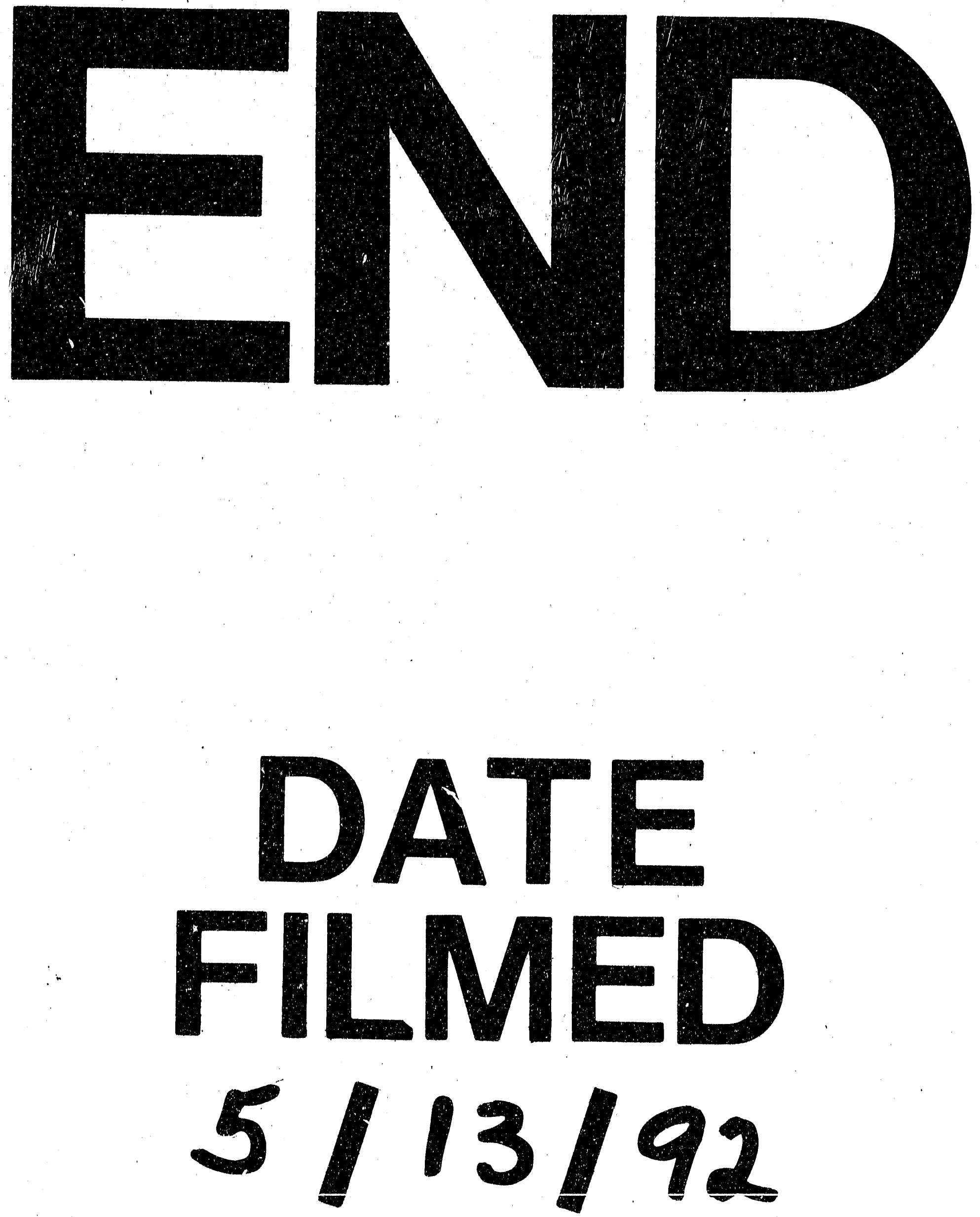
